\section{Gamification in freight transportation: extant corpus and future agenda}

\author{
Ana Carolina Tomé Klock, Eetu Wallius and Juho Hamari \\ Gamification Group, Tampere University, Tampere, Finland
}

Gamification in freight transportation

685

Received 11 April 2020 Revised 25 September 2020 8 February 2021

Purpose - Several freight operations rely on human cognition and behavior. Tackling these aspects,
gamification transforms activities to resemble game-like experiences. Since the freight transportation sector is
rapidly adopting gamification, the purpose of this study is to provide an overview that synthesizes the state-of-
the-art and plot future directions for research and the practice of gamifying this area. Design/methodology/approach - A systematic review of the gamification of freight transportation was conducted. After screening 691 studies, 40 relevant studies were analyzed.

Findings - Most studies found positive psychological and behavioral outcomes from gamification. Literature mainly focused on tackling the operational-level issues of road and maritime transportation modes by implementing simulation games.

Research limitations/implications - Besides elaborating how gamification can improve freight transportation, the authors describe directions still uncovered by the current corpus, such as research design and temporality and the variety of modes and tasks.

Practical implications - Practical implications emerged from the studies, primarily focusing on understanding users, tasks and contexts, targeting different audiences and transportation modalities, and balancing motivational affordances, while considering the demands of the freight transportation domain, including dynamic, spatially dispersed environments and cooperation between multiple stakeholders.

Social implications - The transportation of goods dominates much of the global economy and ecology. Therefore, gamifying this domain has a huge societal impact potential, especially related to issues of sharing economy, safety, environmental sustainability and social media.

Originality/value - Beyond providing an original overview of gamified freight transportation, this study maps current research gaps and describes practical recommendations.

Keywords Gamification, Serious games, Simulation games, Freight transportation,

Systematic literature review

Paper type Research paper

\section{Introduction}

Freight transportation using airways, pipelines, railways, roadways and waterways plays a central role in the global economy (Hesse, 2016). Unsurprisingly, transportation accounts for a significant part of the supply chain expenses (Zeng and Rossetti, 2003), posing a continuous pressure to improve its cost-efficiency. Besides efficiency, transportation systems face challenges related to resilience, safety and sustainability (Kaewunruen et al., 2016). Several technological advances have emerged in recent years to address these challenges, including

(c) Ana Carolina Tomé Klock, Eetu Wallius and Juho Hamari. Published by Emerald Publishing Limited. This article is published under the Creative Commons Attribution (CC BY 4.0) licence. Anyone may reproduce, distribute, translate and create derivative works of this article (for both commercial and noncommercial purposes), subject to full attribution to the original publication and authors. The full terms of this licence may be seen at http://creativecommons.org/licences/by/4.0/legalcode

This work was supported by European Union Regional Development Fund and conducted as a part of the Satadilogis project (A74723) and has been done with affiliation to the Academy of Finland Flagship Forest-Human-Machine Interplay - Building Resilience, Redefining Value Networks and Enabling Meaningful Experiences (UNITE) 337653. \section{February 2021 \\ Accepted 26 February 2021}


IJPDLM

51,7

686 automation (Fagnant and Kockelman, 2015) and data-driven solutions (Hazen and Byrd, 2012; Pei-Ju et al., 2017). Still, many freight transportation processes rely on human factors, as employees are usually responsible for planning and executing them.

One of the approaches for enhancing the human aspect of freight transportation is gamification, which creates game-like systems to support positive experiences (A40) through motivational affordances such as points or leaderboards (Huotari and Hamari, 2017). These affordances contribute to psychological responses (e.g. motivation and engagement) that potentially lead to desired behavioral outcomes (e.g. efficiency and compliance to regulations) (Koivisto and Hamari, 2019). For instance, Klemke et al. (A14) implemented an intervention based on points, levels and rewards to motivate safe and energy-efficient driving, whereas Verbraeck et al. (2016) proposed a game for teaching situational awareness at seaports.

Freight transportation involves a myriad of stakeholders and tasks that could benefit from gamification, including planning, preparation and carriage (Silevičius, 2011), yet the corpus of literature consists of dispersed research fragments. Consequently, there is no comprehensive understanding of how motivational affordances are being applied in this area, which hinders future research endeavors and practical efforts to enhance freight transportation through gamification.

Therefore, this article describes the status quo of the gamification in freight transportation through a systematic literature review. Based on the results, we outline design recommendations and future research avenues, providing academic and practical contributions to the area. To understand if and how gamification influences freight transportation, we organized this article as follows: Section 2 describes related works and our contribution to the literature. Section 3 details the methodology by introducing research questions, keywords, search databases, selection and quality criteria, and the classification scheme employed. Section 4 summarizes the considered aspects of freight transportation, gamified interventions and outcomes. Section 5 discusses practical recommendations and research directions based on the literature. The limitations of this review are discussed in Section 6 . Section 7 concludes with final remarks.

\section{Related works}

Similar systematic reviews exist in this area, but with significant differences regarding their scope and contribution. Wanick and Bui (2019) analyze and provide future directions on gamification and management. While their scope is broader, only four of the studies they include are related to logistics. Even though their results imply that logistics and supply chain strategies are using simulation games for educational purposes, Wanick and Bui (2019) found no evidence that gamification would integrate logistics and supply chain management aspects.

Another related study by Warmelink et al. (2020) focuses on gamification in production and logistics. However, their study adopts a narrower conception of gamification, omitting serious or simulation games. Given the differences in scope, the Warmelink et al. (2020) search returned significantly fewer studies (i.e. 103), and only 18 met the selection criteria. The sole empirical research related to freight transportation included in their analysis also appeared in our search.

Thus, this systematic review is the most comprehensive review undertaken when seeking to create an understanding of how gamification can improve freight transportation. Unlike the related works, our contribution covers: (1) a definition of the current state of the art of gamification within freight transportation and (2) guidance for future developments and research in this domain.

\section{Research methodology}

Systematic reviews assist in theoretical advancement by synthesizing areas where a plethora of research exists and identifying gaps by consolidating the available literature (Webster and 
Watson, 2002). This methodology ensures reproducibility by following a protocol that includes: (1) research questions, (2) keywords and search databases, (3) selection criteria and quality assessment and (4) the classification scheme used to extract data (Petersen et al., 2015). This approach can be regarded as deductive, given that systematic reviews employ an initial predetermined classification scheme based on existing theories. Therefore, this scheme was also iteratively revised during our analysis to include further relevant aspects and to provide better answers to the research questions posed (Seuring and Gold, 2012). Thus, this systematic review comprehensively details the status quo of gamification in freight transportation through the protocol described below.

\subsection{Research questions}

This systematic review aims to understand if and how gamification can influence freight transportation. This broader goal is divided into four research questions:

$R Q 1$. Which aspects of freight transportation employ gamification?

$R Q 2$. What types of gamified interventions and motivational affordances have been implemented in freight transportation?

RQ3. What practical outcomes do these implementations have, and how are they being evaluated?

RQ4. How does gamification support better outcomes in freight transportation?

\subsection{Keywords and search databases}

Potential keywords were identified based on other systematic reviews related to transportation and logistics (Gligor and Holcomb, 2012; Evangelista et al., 2018) or gamification (Baptista and Oliveira, 2019; Koivisto and Hamari, 2019). These included:

(1) Freight transportation: freight, cargo, transport, road, transit, traffic, driving, fleet, aviation, ship, harbor, port, hauling, maritime, pipeline, distribution, delivery, order, demand, operation, supply, logistics, container, stowing, warehouse, storage, inventory, material handling, factory, industry, manufacture.

(2) Gamification: gamification, serious game, simulation game, game.

However, some keywords returned studies that were out of our scope (e.g. game, distribution) or that did not reveal any additional material (e.g. freight, cargo, material handling). After extensive keyword testing, the chosen string was the one whose results matched (gamif*OR "serious gam*" OR "simulation gam*") AND (transport* OR road OR driving OR fleet OR logistics OR warehous* OR factory) in their title, abstract or keywords. Given that no keyword patterns are available for both gamification and freight transportation, we preferred to follow a broader search and filter the results with selection criteria rather than missing relevant studies with a more specific query. We conducted this investigation solely in Scopus, which indexes most databases with potentially relevant content, such as the ACM Digital Library, IEEE Xplore and Springer Link. We used only one search engine to improve rigor, clarity and replicability (Paré et al., 2015). The search returned 691 studies in December 2019.

\subsection{Selection criteria and quality assessment}

Two different readers evaluated each study separately according to predetermined selection criteria. Of these, 103 studies were not conference papers, articles or book chapters; 11 were not written in English; six were not available; seven reported ongoing research without empirical results; 487 were not related to freight transportation; and 17 did not propose 
IJPDLM 51,7

\section{8}

gamified interventions. Most studies were removed as failing to meet the freight transportation-related criteria, given that our broader search returned a significant amount of studies describing non-freight transportation processes such as controlling the supply chain and manufacturing. The inter-rater reliability between the evaluations based on Cohen's kappa coefficient was 0.96 , which is considered an almost perfect agreement (Landis and Koch, 1977). The two evaluators discussed the five dissonant studies and decided to retain them in this literature review.

The 60 studies that met the selection criteria were evaluated through a quality assessment checklist inspired by CASP (2017). The quality evaluation included ten questions based on a three-point Likert scale (being answered $0=$ "No," $0.5=$ "Cannot tell" and $1=$ "Yes"), with a cutoff score of five out of the eight points (i.e. half of the maximum points plus one). While 40 studies met the minimum score, the main quality issues that arose were not describing ethical concerns, or not having a rigorous data analysis. The reviewed studies have been labeled in alphabetical order based on the first author's surname (from A01 to A40 - a total of 40 records). A list of all the reviewed studies is included in the Appendix.

\subsection{Classification scheme}

Besides information about the publication type and year, the 40 studies were classified following the scheme shown in Table 1 . This scheme included freight transportation aspects $(R Q 1)$, gamified interventions and motivational affordances $(R Q 2)$ and evaluation methods and outcomes (RQ3), and an in-depth analysis of gamified approaches toward improving freight transportation $(R Q 4)$ further details the intersection of the previous research questions. These attributes were chosen because of their relevance in providing comprehensive answers to our research questions and also because similar categorizations have been used in prior literature on gamification or freight transportation (Stock and Lambert, 2001; Ghiani et al., 2013; Rushton, 2017; Koivisto and Hamari, 2019), providing more rigor for our analysis.

3.4.1 Freight transportation and logistics. Transportation mode. We considered the primary transportation modes of air, pipeline, rail, road and water (Stock and Lambert, 2001).

Logistic activities. These are typically divided between supplying raw materials and distributing final products (i.e. external), and receiving, storing and picking materials from the warehouse, and packing final products to deliver (i.e. internal) (Ghiani et al., 2013).

\begin{tabular}{|c|c|c|}
\hline & Attribute & Categories \\
\hline \multirow[t]{3}{*}{ Freight transportation aspects } & $\begin{array}{l}\text { Transportation } \\
\text { mode }\end{array}$ & Air, pipeline, rail, road, water \\
\hline & Logistics activities & External, internal \\
\hline & $\begin{array}{l}\text { Decision-making } \\
\text { level }\end{array}$ & Operational, tactical, strategic \\
\hline \multirow[t]{2}{*}{$\begin{array}{l}\text { Gamified interventions and } \\
\text { motivational affordances }\end{array}$} & $\begin{array}{l}\text { Type of } \\
\text { intervention }\end{array}$ & Simulation game, serious game, gamification \\
\hline & $\begin{array}{l}\text { Motivational } \\
\text { affordances }\end{array}$ & $\begin{array}{l}\text { Achievement, immersion, social, non-digital, } \\
\text { miscellaneous }\end{array}$ \\
\hline \multirow{4}{*}{$\begin{array}{l}\text { Evaluation methods and } \\
\text { outcomes }\end{array}$} & Research approach & Qualitative, quantitative, mixed \\
\hline & Research strategy & Observational, experimental \\
\hline & $\begin{array}{l}\text { Data collection } \\
\text { method }\end{array}$ & $\begin{array}{l}\text { Interview, focus group, participant observation, pre- } \\
\text { and post-test, questionnaire or survey, interaction log }\end{array}$ \\
\hline & Outcomes & Psychological, behavioral \\
\hline
\end{tabular}

Table 1.

Summary of the classification scheme 
Decision-making level. Levels of planning and control are hierarchically divided based on their time horizons (Rushton, 2017): Operational concerns daily and weekly planning to ensure short-term efficiency. Tactical refers to using available resources allocated in annual budgets, having medium-term effects. Strategic encompasses significant investments, leading to longterm outcomes.

3.4.2 Gamification. Type of intervention. Besides being an umbrella term for game-based approaches (Hamari, 2019), gamification more specifically refers to using the motivational affordances commonly present in games as part of a more extensive system (Deterding et al., 2011; Huotari and Hamari, 2017). A further two gamification categories were considered: simulation games, which are game-like environments that simulate real-life processes (Ellington et al., 1981), and serious games, describing full-fledged games whose primary goal is not entertainment (Michael and Chen, 2006).

Motivational affordances. The different game design dimensions can be categorized as achievement, immersion or social components (Yee, 2006). Achievement components measure the player's progress (e.g. challenges, points, performance stats and feedback, increasing difficulty, levels, badges, leaderboards, timers). Immersion components are related to fantasy and customization (e.g. role-play, narrative, rewards, virtual worlds, avatars). Finally, social components enable relationships and teamwork (e.g. cooperation, competition, multiplayer, social networks). Motivational affordances that do not fit these categories have been classified by Koivisto and Hamari (2019) as non-digital elements (e.g. physical playboards, cards and dice) and miscellaneous (e.g. virtual currencies, game rounds, retries, onboarding and augmented reality - AR).

3.4.3 Evaluation methods and outcomes. Research approach. Studies focused on understanding the meaning an individual or group ascribe to a problem (i.e. qualitative), testing theories by examining relationships among variables (i.e. quantitative) or both (i.e. mixed-method) (Creswell, 2014).

Research strategy. Studies were also categorized as observational or experimental. Observational studies had no deliberate human intervention, while experimental ones involved a planned intervention based on factors suspected to influence the studied phenomenon (Schlesselman, 1982).

Data collection method. Results were drawn from some of the most common methods, including interviews, focus groups, participant observations, pre-and post-tests, questionnaires or surveys and logs analysis (Lethbridge et al., 2005).

Outcomes. Gamification can promote both psychological and behavioral reactions (Huotari and Hamari, 2017). There are diverse gamification psychological outcomes, such as game experience, perceived learning, perceived usefulness, perceived reality, motivation, fun, engagement, satisfaction and attitude, categorized according to the scheme of Koivisto and Hamari (2019). Meanwhile, the behavioral outcomes are related to efficiency (e.g. time to complete a task), sustainability (e.g. learning about environmental effects), resilience (e.g. improving decision-making during disruptions) and safety (e.g. learning to design safer transportation infrastructures).

\section{Results}

Gamified freight transportation is an emergent research topic that has received attention over the past ten years. Most studies were published in conferences $(n=27)$ and journals $(n=17)$. The emphasis on conferences suggests that this topic is still at an early stage, given they usually have space constraints, preventing the presentation of detailed results and discussion. Concerning the material origin, $75 \%$ of the studies were written by authors affiliated to European institutions, mainly from The Netherlands $(n=17)$ and Germany $(n=7)$. Furthermore, most studies were published in different venues, except for the 
IJPDLM 51,7
Simulation and Gaming journal that had two articles, and the International Conference on Games and Learning Alliance and International GamiFIN Conference that had three papers each. The scope of the venues was related to gamification (36\%), education (27\%), supply chain (18\%), technology and innovation (14\%) and sustainability (5\%).

\subsection{Freight transportation aspects (RQ1)}

The literature mostly explored road and water modes, which are the most common freight transportation modes used inside Europe (European Union, 2019), from where the majority of the authors were affiliated. Most studies (65\%) considered a single mode, but some used two (A09, A19), three (A06, A18, A20) and four (A17, A23) modes simultaneously. Moreover, 13 studies (A02, A04, A13, A15, A16, A29, A30, A31, A32, A33, A34, A35, A38) did not explicitly specify the investigated transportation mode. The lack of pipeline-related studies is likely due to its massive automatization, requiring little human intervention (Liu, 2003), and therefore, demanding less motivational interventions, including gamification (Figure 1).

Most studies focused on external logistics $(60 \%)$. Together with the eight studies simultaneously gamifying external and internal logistics, $80 \%$ of the studies attempted to enhance external logistics by improving, for example, their safety, sustainability or resilience. Studies exploring both external and internal logistics mainly described gamified applications for strengthening the entire supply or logistics chain (A01, A06, A11, A23, A24, A27, A36, A38). Eight studies were exclusively about internal logistics (A02, A04, A13, A29, A31, A32, A34, A35).

The majority of the studies proposed operational-level interventions, including planning and execution, as detailed in Table 2. Operational planning mainly pursued training users to handle complex situations such as disruptions at maritime ports (A37) or coordinating humanitarian logistics (A24). Operational execution focused on enhancing day-to-day functions such as truck driving (A12, A14, A28) and stevedoring (A07), tasks often considered as monotonous (Tabai et al., 2017) and accident-prone (Loeb and Clarke, 2007;

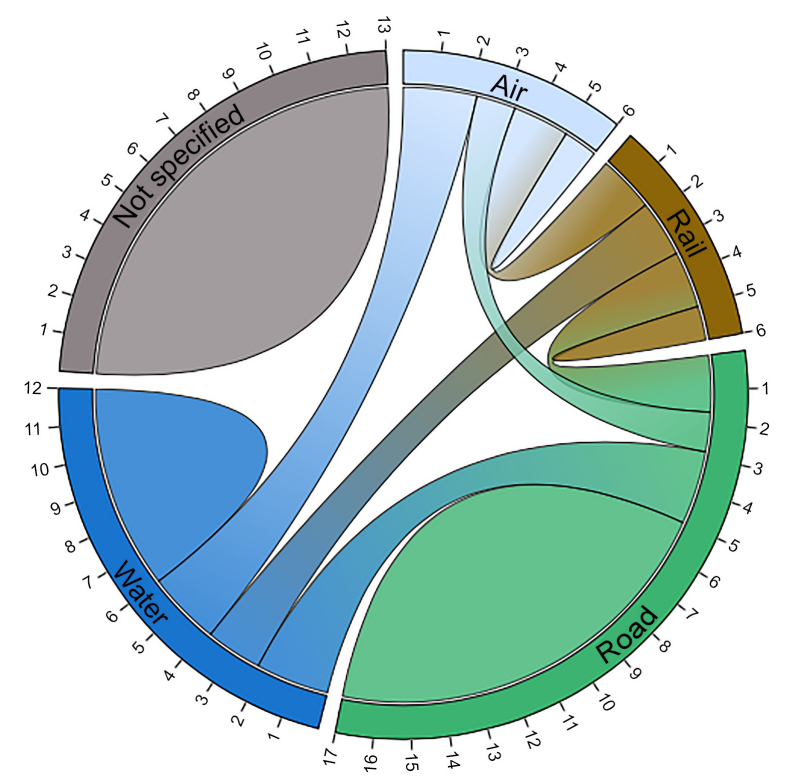

Figure 1.

Transportation modes according to the number of studies 
Shang and Tseng, 2010). Tactical studies aimed to maximize profits by optimizing the available resources (A05) or training for decision-making related to resource acquisition (A01). Strategic studies focused on long-term investments such as port (A03) or automated container terminal (A10) construction and highway design (A39, A40). Three studies covered short to medium-term horizons (A18, A31) and medium to long terms (A36), while one study (A33) did not describe the decision-making level. Regarding the target audience, the interventions mostly focused on students (A02, A03, A04, A05, A07, A09, A11, A13, A15, A16, A22, A23, A24, A25, A26, A31, A33, A36, A37, A38, A39, A40); transportation professionals, such as drivers and air traffic managers (A01, A03, A09, A10, A12, A14, A15, A16, A18, A19, A21, A22, A25, A28, A29, A32, A34); and stakeholders such as clients and citizens (A06, A08, A18, A20, A27, A30, A35).

\subsection{Gamified interventions and motivational affordances (RQ2)}

Most studies used simulation games, either considering the authors' definition $(n=23)$ or the intervention description (i.e. a gaming solution mimicking a real-world environment and circumstances accurately - Ellington et al., 1981) $(n=26)$. Five studies (A08, A09, A12, A13, A15) defined themselves as "serious games" (i.e. full-fledged games not aiming to mimic realworld circumstances but use fictional representations) but described solutions that mimic real-life events (i.e. simulation games). Three studies (A38, A39, A40) defined their solutions as gamified interventions (i.e. using game elements without providing a full-fledged game Deterding et al., 2011), but described full-fledged educational games (i.e. serious games). Still, Figure 2 shows the interventions to be mostly full-fledged games, which is expected given that game-like experiences began to emerge from 2014 onward (A14, A30, A32, A33, A34).

Each study presented between 2 and 12 motivational affordances. Most studies focused on achievement components (41\%), followed by immersion (19\%) and social (18\%) components, which is a pattern seen in gamification literature as a whole (Koivisto and Hamari, 2019). When analyzing each affordance, challenges (14\%), points $(9 \%)$, role-play $(9 \%)$ and cooperation (8\%) were the most used, as depicted in Figure 3.

\subsection{Evaluation methods and outcomes (RQ3)}

Mixed $(48 \%)$ or qualitative (38\%) approaches were predominant, implying that the studies are still assessing whether gamification is beneficial rather than measuring its impact. Meanwhile, quantitative studies measured gamification's effects regarding knowledge acquisition (A33, A37, A39, A40) and performance increase (A21, A29, A33).

Studies were mainly observational $(78 \%)$ due to the few purely quantitative studies available. Quantitative studies employed experimental settings in which participants were either using all conditions (i.e. within-subjects, as seen in A37 and A12) or only one (i.e. between-subjects, as seen in A04, A23, A26, A33, A39, A40). The comparison of the results was expressed in terms of employed motivational affordances (A04, A37), different games (A39, A40) or user characteristics (A26) and gamified versus non-gamified interventions

\begin{tabular}{|c|c|c|c|}
\hline $\begin{array}{l}\text { Decision-making } \\
\text { level }\end{array}$ & Studies & Total & \\
\hline Operational & $\begin{array}{l}\text { A04, A07, A08, A09, A12, A13, A14, A15, A16, A17, A18, A19, A20, A22, } \\
\text { A24, A25, A27, A28, A29, A30, A31, A32, A34, A35, A37 }\end{array}$ & $25(58 \%)$ & Table 2. \\
\hline Tactical & A01, A05, A11, A18, A21, A31, A36 & $7(16 \%)$ & Decision-making level \\
\hline Strategic & $\mathrm{A} 02, \mathrm{~A} 03, \mathrm{~A} 06, \mathrm{~A} 10, \mathrm{~A} 23, \mathrm{~A} 26, \mathrm{~A} 36, \mathrm{~A} 38, \mathrm{~A} 39, \mathrm{~A} 40$ & $10(24 \%)$ & of the gamified \\
\hline Not specified & A33 & $1(2 \%)$ & interventions \\
\hline
\end{tabular}

Gamification in freight transportation 


\section{IJPDLM \\ 51,7}

\section{2}

Figure 2.

Difference between semantic and authors' definitions of the interventions

Figure 3.

Composition of the motivational

affordances reported by the studies

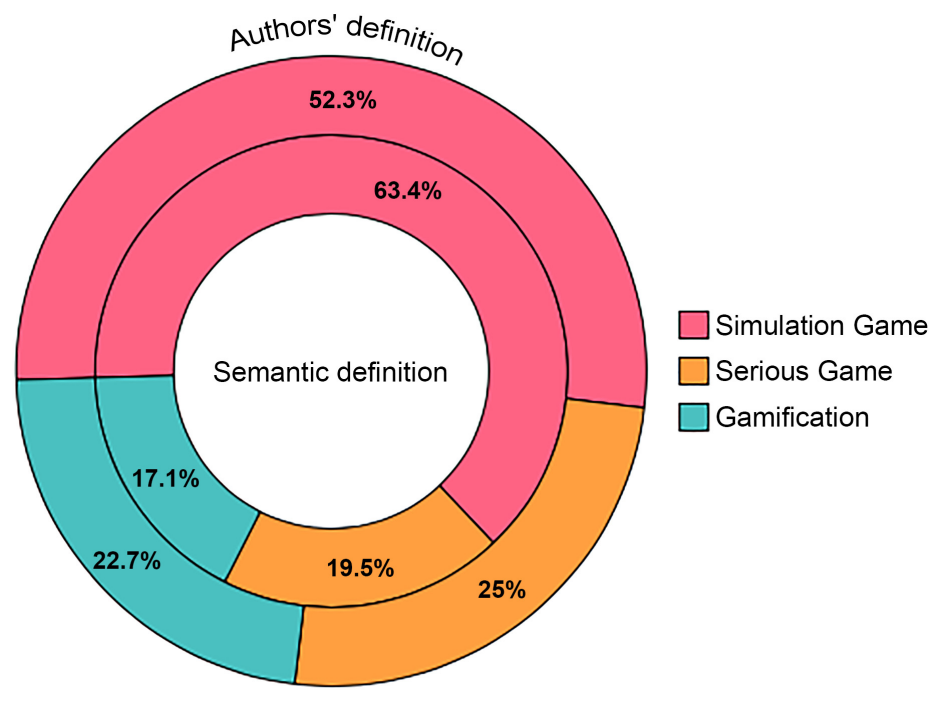

Achievement $(n=98)$

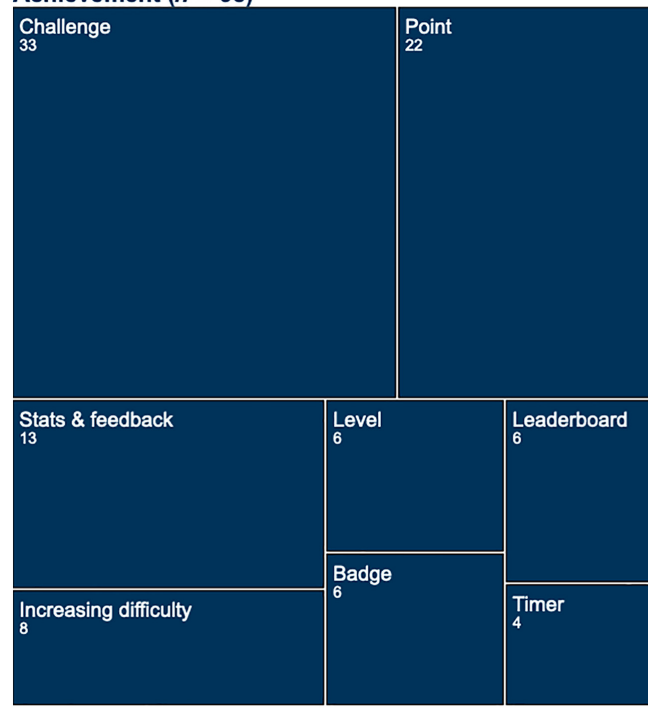

Miscellaneous ( $n=33$ )

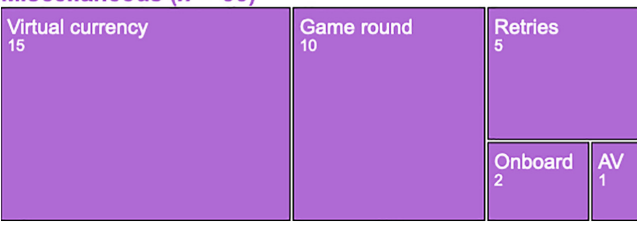

Immersion $(n=44) \quad$ Social $(n=42)$

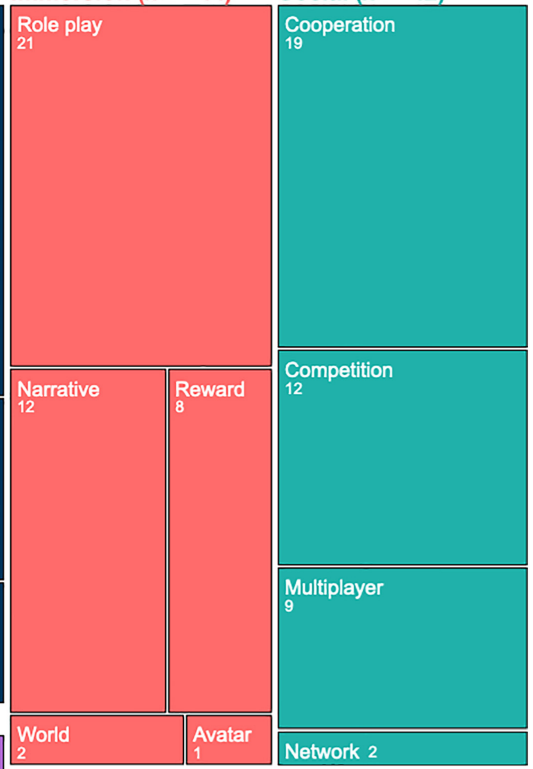

Non-digital $(n=20)$

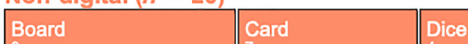


(A12, A23, A33). These experimental studies were the only ones to infer relationships between variables (i.e. inferential statistics) rather than using quantitative methods to describe the dataset (i.e. descriptive statistics).

Questionnaires or surveys were the most used data collection methods (68\%), followed by participant observation (35\%) and interaction logs (25\%). Studies employed a total of 66 methods, with a maximum of four different ones featured in a single study (A03, A16, A18). Three studies (A11, A14, A36) did not specify their data collection methods.

Thirty studies $(75 \%)$ analyzed psychological outcomes, and eight $(20 \%)$ behavioral outcomes. Two studies did not report any psychological or behavioral effects, as they proposed methods (A10) and processes (A15) for game design. Meanwhile, quantitative studies defined metrics to verify behavioral outcomes, such as correctness rate (A33, A39, A40) and task completion time (A37, A04, A09, A24) to measure efficiency. The most common psychological outcomes include game experience, perceived learning, perceived usefulness and perceived reality, and the most studied behavioral outcome was efficiency, as detailed in Table 3. Outcomes were statistically negative/positive (with inferential analysis), negative/ positive (qualitative or without statistically significant differences) or mixed (related neutral or discordant results).

One study (A28) described outcomes other than psychological and behavioral ones by identifying positive effects in helping truckers suffering from post-traumatic stress disorder (i.e. mental health). Regarding motivation in order-picking scenarios, gamification had a statistically negative impact on competence and relatedness, whereas there were no

\begin{tabular}{|c|c|c|c|c|c|c|}
\hline & $\begin{array}{l}\text { Statistically } \\
\text { negative }\end{array}$ & Negative & Mixed & Positive & $\begin{array}{l}\text { Statistically } \\
\text { positive }\end{array}$ & \\
\hline \multicolumn{7}{|l|}{ Psychological outcome } \\
\hline $\begin{array}{l}\text { Game experience } \\
(n=10)\end{array}$ & 0 & 0 & $\begin{array}{l}4(\mathrm{~A} 06, \\
\mathrm{A} 19, \mathrm{~A} 20, \\
\mathrm{~A} 31)\end{array}$ & $\begin{array}{l}5 \text { (A08, A09, A11, } \\
\text { A22, A35) }\end{array}$ & 1 (A23) & \\
\hline $\begin{array}{l}\text { Perceived learning } \\
(n=7)\end{array}$ & 0 & 0 & 0 & $\begin{array}{l}7 \text { (A03, A07, A18, } \\
\text { A25, A27, A31, } \\
\text { A35) }\end{array}$ & 0 & \\
\hline $\begin{array}{l}\text { Perceived usefulness } \\
(n=7)\end{array}$ & 0 & 0 & 0 & $\begin{array}{l}7 \text { (A09, A14, A22, } \\
\text { A30, A32, A34, } \\
\text { A36) }\end{array}$ & 0 & \\
\hline $\begin{array}{l}\text { Perceived reality or } \\
\text { immersion }(n=7)\end{array}$ & 0 & 1 (A25) & 0 & $\begin{array}{l}6 \text { (A08, A12, A24, } \\
\text { A27 A28, A31) }\end{array}$ & 0 & \\
\hline Motivation $(n=6)$ & $1(\mathrm{~A} 04)$ & 0 & 1 (A04) & $\begin{array}{l}4 \text { (A09, A19, A25, } \\
\text { A27) }\end{array}$ & 0 & \\
\hline $\begin{array}{l}\text { Fun or entertainment } \\
(n=5)\end{array}$ & 0 & 0 & 0 & $\begin{array}{l}5 \text { (A08, A18, A25, } \\
\text { A31, A32) }\end{array}$ & 0 & \\
\hline Engagement $(n=4)$ & 0 & 0 & 0 & $\begin{array}{l}4 \text { (A05, A19, A24, } \\
\text { A34) }\end{array}$ & 0 & \\
\hline Satisfaction $(n=4)$ & 0 & 0 & 1 (A23) & 3 (A02, A12, A38) & 0 & \\
\hline Attitude $(n=3)$ & 1 (A23) & 0 & 0 & $2(\mathrm{~A} 19, \mathrm{~A} 30)$ & 0 & \\
\hline \multicolumn{7}{|l|}{ Behavioral outcome } \\
\hline Efficiency $(n=7)$ & 0 & 0 & 0 & $\begin{array}{l}4 \text { (A06, A16, A18, } \\
\text { A37) }\end{array}$ & $\begin{array}{l}4(\mathrm{~A} 04, \mathrm{~A} 37 \\
\mathrm{A} 39, \mathrm{~A} 40)\end{array}$ & \\
\hline Resilience $(n=2)$ & 0 & 0 & 0 & $2(\mathrm{~A} 16, \mathrm{~A} 18)$ & 0 & \\
\hline Safety $(n=2)$ & 0 & 0 & 0 & 0 & $2(\mathrm{~A} 39, \mathrm{~A} 40)$ & \\
\hline Sustainability $(n=2)$ & 0 & 0 & 0 & 1 (A16) & 1 (A33) & Table 3. \\
\hline $\begin{array}{l}\text { Total of different } \\
\text { studies }\end{array}$ & 2 & 1 & 6 & 26 & 6 & $\begin{array}{r}\text { Psychological and } \\
\text { behavioral outcomes }\end{array}$ \\
\hline
\end{tabular}

Gamification in freight transportation

693 
IJPDLM

51,7

differences in autonomy (A04). Gamification significantly improved knowledge acquisition regarding sustainability, while positive results had no statistical difference over knowledge retention (A33). When analyzing efficiency, there were statistical differences over some metrics (e.g. profit and operational costs), but others (e.g. time to complete tasks), while positive, had no statistical support (A37).

\section{4}

\subsection{Gamified approaches toward improving freight transportation (RQ4)}

According to decision-making levels and gamified approaches, interventions targeted different transportation aspects. For instance, simulation games were employed in all decision-making levels to address both psychological (i.e. game experience, perceived reality, perceived learning, fun, engagement, motivation, perceived usefulness, satisfaction and attitude) and behavioral (i.e. efficiency and resilience) shortcomings. Despite having majorly positive outcomes within the 12 operational-level interventions, three cases described mixed game experience results for simulation game interventions (A19, A20, A31). While all three games had one affordance in common (i.e. points), we cannot state that it was responsible for the mixed effect, given that other studies (A08, A09, A22, A35) found positive game experience results employing points.

Meanwhile, A25 reported that their simulation game to support learning using achievement (i.e. challenge, points) and immersion (i.e. narrative, reward) affordances harmed perceived reality. All of the other employed motivational affordances had positive effects on the evaluated metrics. Figure 4 illustrates the relationship between affordances and outcomes, in which the size represents the number of studies, and the color describes the effect.

Regarding the tactical level, two studies described simulation games to schedule and optimize shipping (A11) and maximize the profits (A05) in road transportation, which positively influenced players' game experiences and engagement, respectively. Both games employed challenge, competition and narrative, while A11 also used cooperation and A05 game round and role-play.

Five strategic-level simulation games aimed to teach supply chain and logistics operation management (A02, A06, A23, A36), or to simulate the development of a new area in a maritime port (A03). They evaluated their effects on game experience (A06, A23), satisfaction (A02, A23), attitude (A23), efficiency (A06), perceived learning (A03) and perceived usefulness (A36). The outcomes were positive overall, except for mixed results on satisfaction (A23) and game experience (A06), as shown in Figure 5.

Meanwhile, serious games focused on operational and strategic decision-making levels toward increasing efficiency, game experience, perceived learning, safety, motivation, perceived reality, resilience, satisfaction and sustainability, as shown in Figure 6. Operational-level interventions had solely positive effects on efficiency, perceived learning, resilience, sustainability and motivation by employing achievement (i.e. challenge, points, increasing difficulty, timer, leaderboard), immersion (i.e. reward, role-play, narrative), social (i.e. cooperation, competition), miscellaneous (i.e. game rounds, virtual currency) and nondigital (i.e. board, card) affordances. Strategic-level games had positive results for efficiency, safety and satisfaction, with mixed results only for the game experience, since the simulation game described in A06 is also serious. The motivational affordances used included achievement (i.e. challenge, level, points, stats), immersion (i.e. role-play, narrative, world), social (i.e. competition, cooperation) and miscellaneous (i.e. retry, virtual currency), but no non-digital affordances.

Gamified solutions were only applied at the operational level to address perceived usefulness, engagement, motivation, attitude, efficiency and fun, as presented in Figure 7. Gamification adopted achievement (i.e. badge, challenge, leaderboard, level, points, stats), 


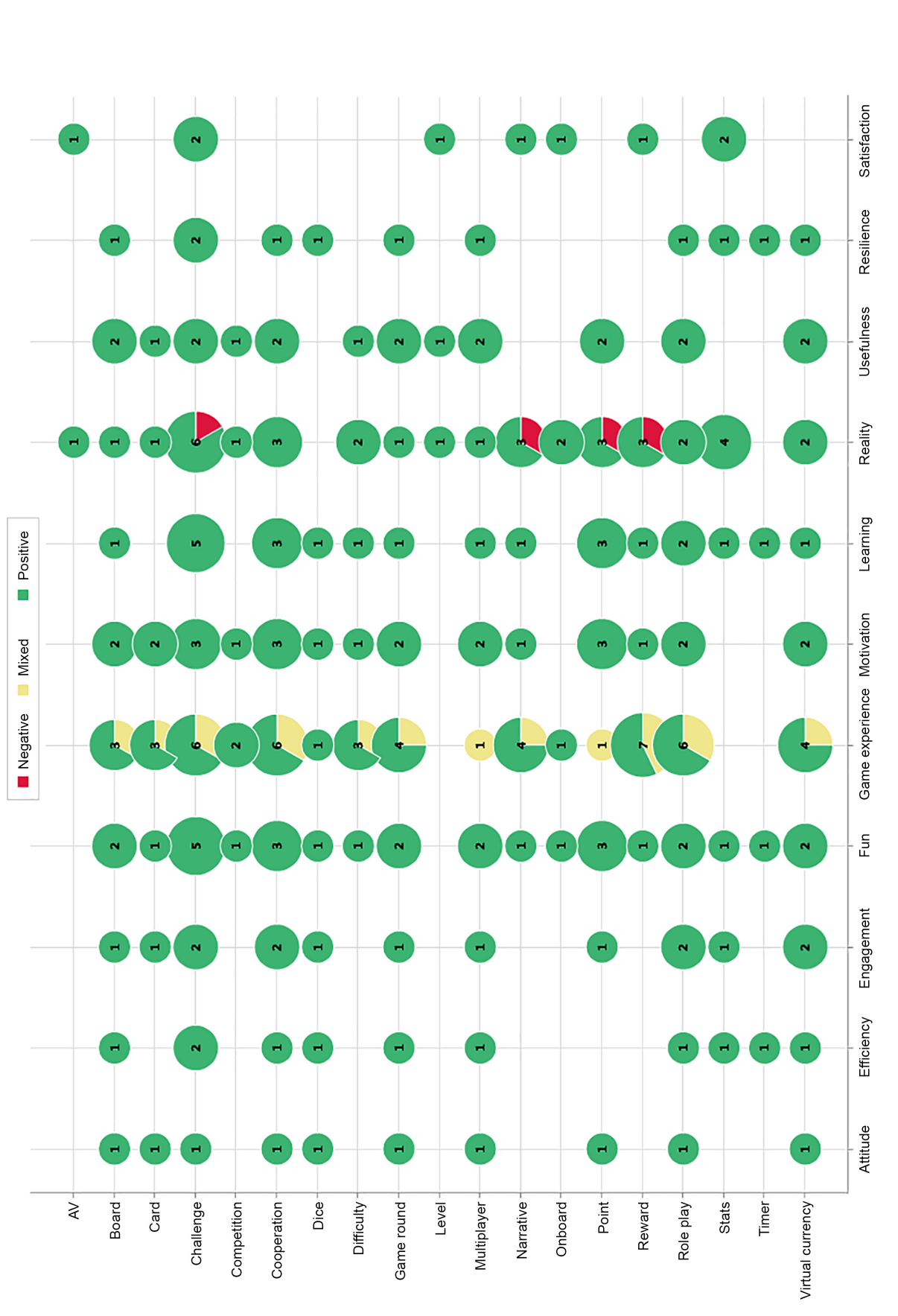

Gamification in freight transportation

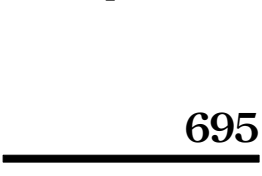

695 Affordances of operational-level simulation games by outcome 
IJPDLM

51,7

696

Figure 5.

Affordances of

strategic-level

simulation games by outcome

Figure 6.

Affordances of operational- and strategic-level serious games by outcome
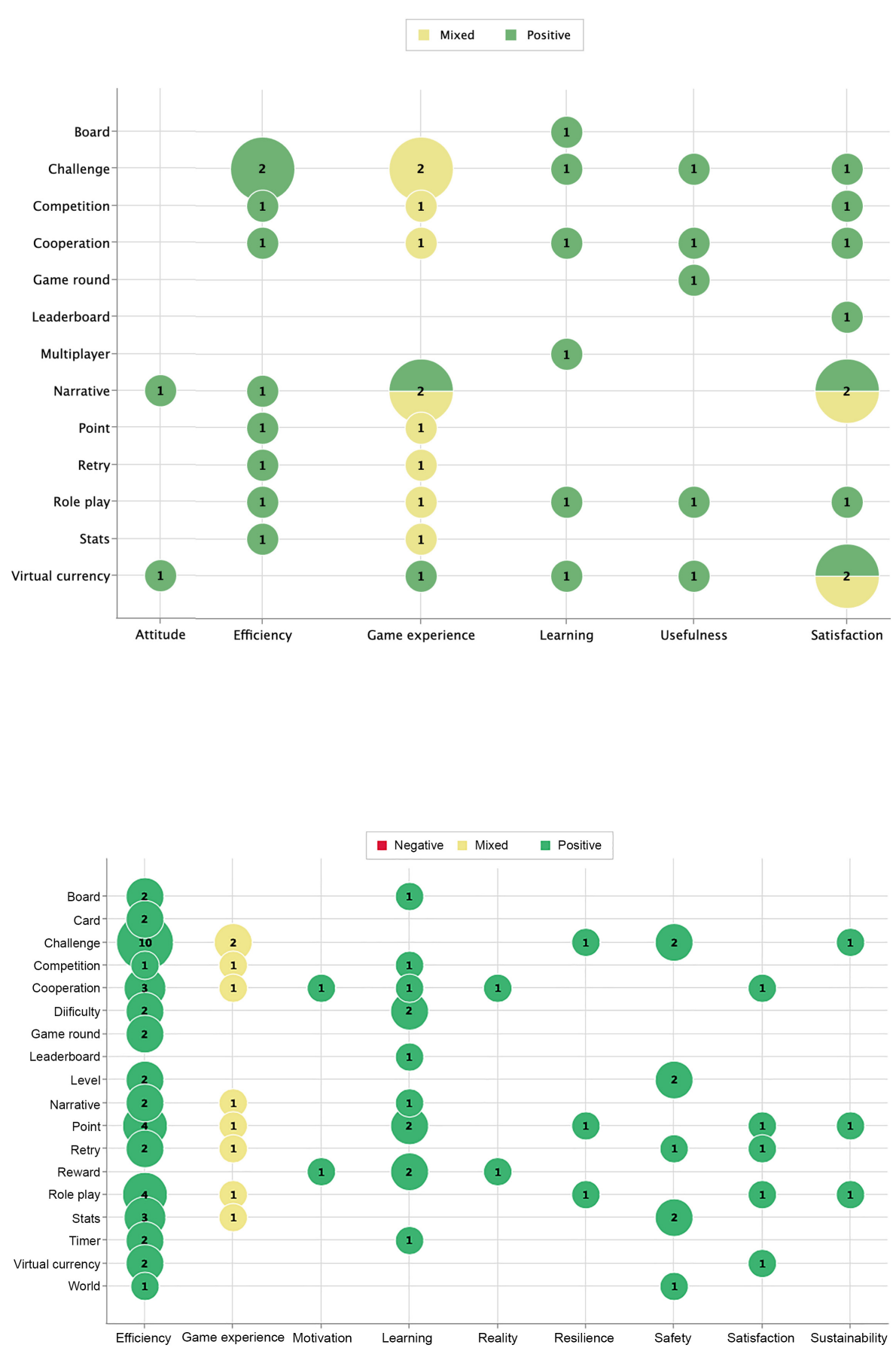


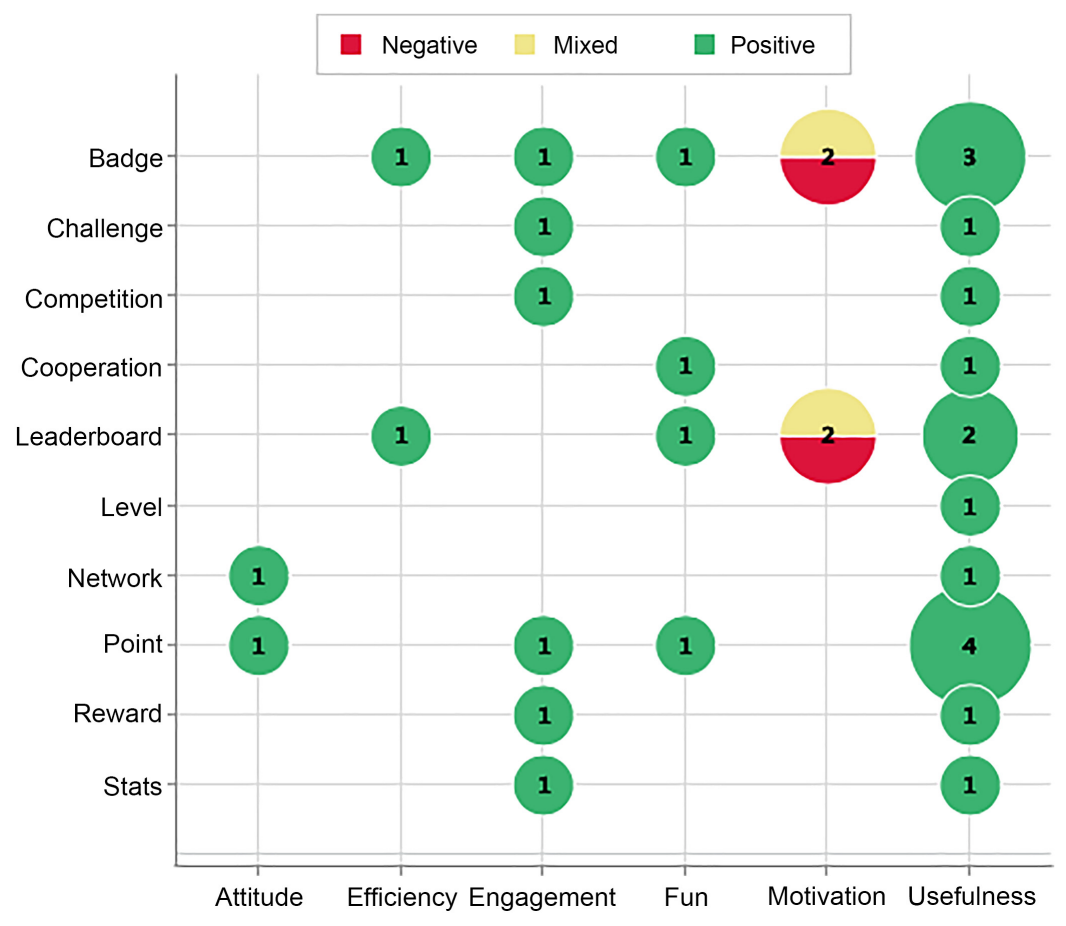

Gamification in freight transportation

697

Figure 7. Affordances of operational-level gamification by outcome

social (i.e. competition, cooperation, network) and immersion (i.e. reward) affordances, while not implementing any non-digital and miscellaneous affordances. While having predominantly positive effects, A04 reported the sole negative and mixed outcomes by applying badges and leaderboards to warehouse order-picking: leaderboards harmed competence and relatedness aspects, and badges also harmed relatedness.

Regardless of the decision level and intervention type, game experience was mostly positively influenced by challenges, points, cooperation, role-play, virtual currency, competition, game rounds, multiplayer, narrative, boards, cards and increasing difficulty (A06, A08, A09, A11, A19, A22, A31, A35). Of these, five studies reported mixed results, since 13 government officials had difficulties in mastering game rules (A06), 24 logistics experts faced interruptions (A19), 12 transport infrastructure managers had mixed perceptions of a corridor management simulation game (A20) and 35 students had mixed experiences of simulation games used in a university logistics course (A31).

In regard to successfully improving knowledge, some studies employed challenges, stats, retries, role-play, competition, cooperation, levels, narrative, points and timers (A06, A16, A18, A33, A39, A40). Perceived learning also had exclusively positive outcomes by employing challenges, cooperation, points, rewards, role-play, boards, multiplayer, narrative, timer and virtual currency (A03, A07, A18, A25, A27, A31, A35). Perceived usefulness results were only positive using points, challenges, badges, cooperation, game rounds, role-play, virtual currency, boards, competition, leaderboards, levels and multiplayer (A09, A14, A22, A30, A32, A34, A36).

Meanwhile, the perceived reality was mostly positive when applying challenges, cooperation, rewards, narrative, points, increasing difficulty, onboard, role-play, stats and virtual currency (A08, A12, A24, A25, A27, A28, A31). Of these, A25 was the only study 
IJPDLM 51,7

\section{8}

Figure 8.

Amount of studies analyzing each psychological outcome by each affordance reporting negative results over perceived reality by analyzing the effects of a simulation game to support situated learning in the workplace with 83 logistics specialists and students who used challenges, narrative and rewards. The participants indicated the game could have been more realistic, and that the background music was disturbing.

Studies reported positive effects in using challenges, role-play, competition, cooperation, game rounds, points, stats and virtual currency (A05, A19, A24, A34) toward improving engagement. Some authors also aimed to promote fun through challenges, cooperation, points, boards, game rounds, multiplayer, role-play and virtual currency (A08, A18, A25, A31, A32), and achieved exclusively positive outcomes.

Some studies managed to improve motivation by using challenges, cooperation, points, boards, cards, game rounds, multiplayer, rewards, role-play and virtual currency (A09, A19, A25, A27). Toward improving satisfaction, studies using narrative, virtual currency, challenges, cooperation, role-play (A02, A12, A23, A38) had majorly positive results, except for the mixed results reported by A23 using narrative and virtual currency. Two studies also analyzed the effects of points and virtual currency (A19, A23, A30) toward improving attitude. The negative impact of virtual currency reported by A19 led to mixed results, as participants had difficulties using the game currency correctly.

Overall, using most of the motivational affordances, especially challenges, points and cooperation, improved psychological outcomes, as shown in Figure 8. However, this evidence is far from being a silver bullet, given the divergent contexts, sample sizes, implementations,

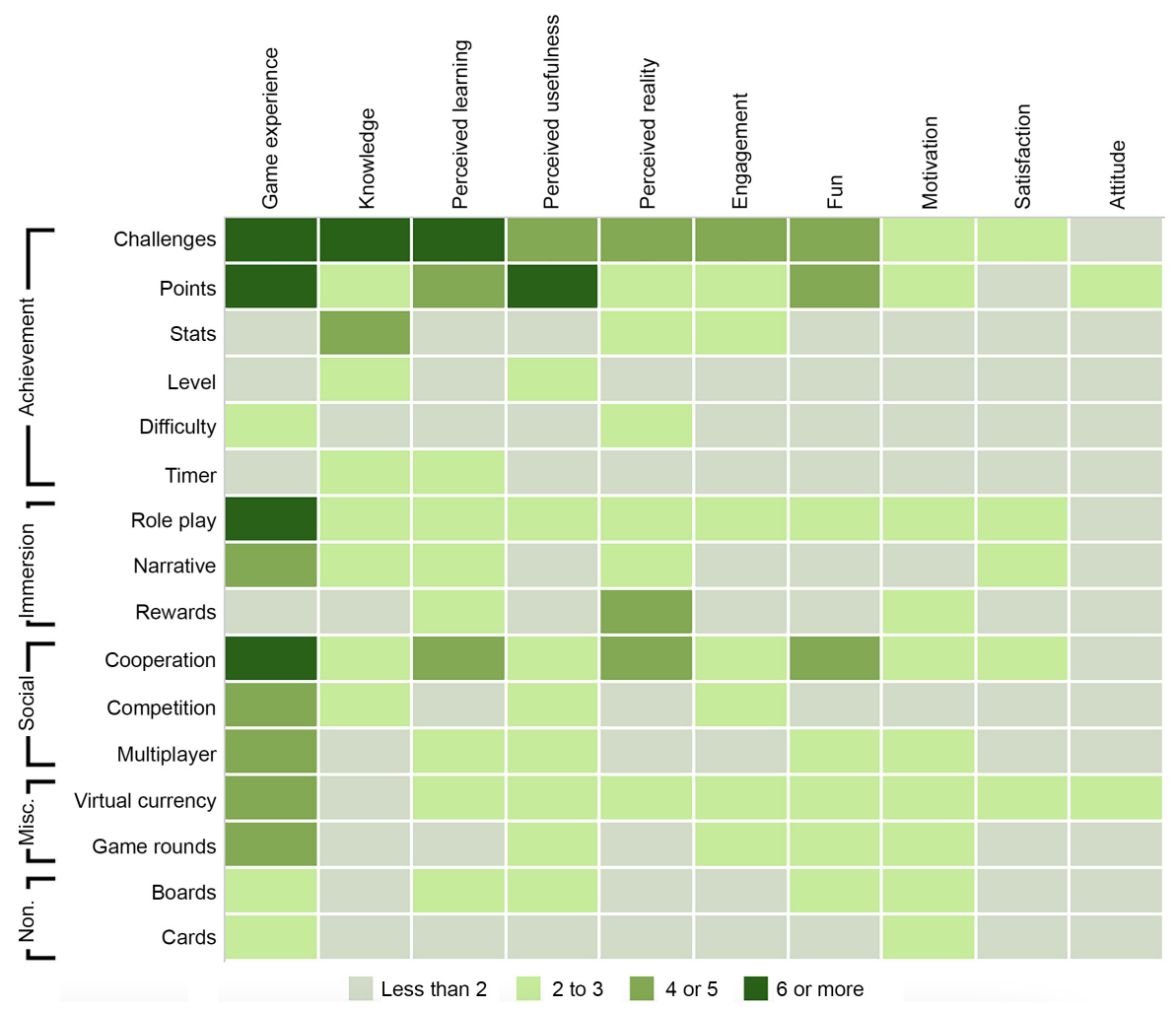


data collection and evaluation methods applied. Also, there were no motivational affordances used more than once while investigating behavioral outcomes.

In a broader sense, these positive psychological effects resonate with theoretical literature, such as self-determination (Ryan et al., 2006), goal-setting (Locke and Latham, 1990), flow (Csikszentmihalyi, 1993) and social learning theories (Bandura, 1986). The self-determination theory explains how achievement affordances (e.g. challenges, points) assist in the sense of competence. Immersion affordances (e.g. role-play, narrative) endorse autonomy, and social affordances (e.g. cooperation, competition) encourage relatedness, which are all universal and innate human needs. The goal-setting theory also explains why achievement affordances were the most used, since they would help in ensuring a focus on relevant targets with the use of challenges, providing ongoing feedback with stats and adjusting demanded effort with increasing difficulty. The flow theory describes a mental state where the individual is fully engaged with an activity, supported by achievable tasks, clear goals and feedback (i.e. achievement affordances), but also by concentration and a reduced sense of self and time (i.e. immersion affordances). The social learning theory also supports positive gamification outcomes with social affordances since it assumes learning takes place in a social context and relies on observation (e.g. multiplayer) or communication with others (e.g. cooperation, competition). Even though the corpus did not reveal patterns toward behaviors, the theory also supports positive outcomes featured in Table 3. For instance, the behavioral decision theory, which is focused on human decision-making and usually applied in the transportation area (Takemura, 2014), explains how gamification increases the learning level (e.g. difficulty) and provides information to assist in the decision process (e.g. stats).

However, gamified solutions did not always improve the game experience, motivation, attitude, satisfaction or perceived reality, which implies that translating theoretical predictions into the gamification design is not straightforward. While gamification strives to address human needs through the interplay between motivational affordances and psychological responses, this interplay is complex due to the synergy that arises in implementing multiple affordances (Morschheuser et al., 2018). This complexity makes it difficult to predict user responses, leading to unexpected and even possibly unfavorable outcomes. For example, implementing points or challenges can create a sense of competence, but lead to a game design that is more difficult to grasp, thus hindering game experience (A06). Additionally, users have heterogeneous preferences, and affordances motivating or improving the game experience for some might be perceived as undesirable by others (A26). This further complicates the endeavor to design successful gamified solutions.

\section{Discussion}

The studied literature employed gamification in the leading freight transportation modes, focusing on external logistics and covering all decision-making levels. Hence, the corpus reflects the multifaceted nature of freight transportation by exploring gamification effects in its various human-performed aspects.

Most studies (65\%) employed simulation games for situations requiring efficient decisionmaking (e.g. port disruptions (A15), multimodal planning (A20, A22)), enhancing the holistic understanding of supply chains (e.g. visual interactive learning to provide feedback on the effects of strategic-level decisions (A2)) and influencing users' mental models (e.g. predicting future states of complex logistics systems (A3)). The focus on three main types of motivational affordances suggests that these solutions aim to provide experiences that tackle the relatedness aspect of intrinsic motivation, provide performance feedback and allow the user to feel they are part of a game world. Thus, they offer a meaningful and effective way for promoting behaviors related to the human aspects of transportation while allowing the user to form and test hypotheses and reflect upon the simulated environment (Hamari et al., 2016;
Gamification in freight transportation

699 
IJPDLM

51,7

700

Koivisto and Hamari, 2019; Ryan et al., 2006; Yee, 2006). Moreover, social affordances (e.g. multiplayer, collaboration) allow distributed learning and shared situational awareness among multiple stakeholders, which improves efficiency, resilience and sustainability in situations where optimization at an individual level leads to poor decision-making due to conflicting goals (A08, A09, A15, A22, Boy, 2013). In addition to teaching collaborative situational awareness and decision-making, simulation games can implement multiplayer and collaboration to analyze human behavior in situations that require collaborative problem-solving, such as crisis supply chain management (A24).

Serious games focused on achievement affordances (e.g. challenges, goals) to improve efficiency by allowing users to explore the effects of different resource allocation strategies (A06, A37) and learn design concepts through simplified representations (A39, A40). According to the goal-setting theory (Locke and Latham, 1990), setting goals provides a useful tool for enhancing performance, especially if they provide an adequate challenge, which explains the focus on achievement affordances. Moreover, goal-setting can support strategies that lead to better learning outcomes, which is often the underlying goal of serious gaming interventions and likely explains the positive learning results found (Ames and Archer, 1988; Michael and Chen, 2006; Seijts et al., 2004). Additionally, similar to many simulation games, some serious games implemented social affordances to enhance shared mental models, distributed situational awareness and collaborative logistics coordination (A27, A37).

Meanwhile, gamified interventions focused on enhancing usefulness by mainly implementing points, badges and leaderboards, which are some of the most used affordances in gamification research (Koivisto and Hamari, 2019). Results indicate that gamified interventions contribute to the adoption of novel systems in transportation settings by creating engaging and useful interfaces (A30, A34) while also improving learning (A33) and tackling monotonous tasks by enhancing staff motivation and enjoyment (A04, A32). This approach commonly leads to favorable results, but undermining intrinsic motivation is a risk to be considered (A04). The authors of the sole study reporting negative outcomes on motivation implemented a leaderboard (A04) and stated that the adverse effects on relatedness and competence might be explained by its design as a competitive instead of cooperative approach. However, despite adverse effects, implementing a leaderboard improved efficiency, which is a finding that resonates with a prior study suggesting that individual performance does not mirror intrinsic motivation (Mekler et al., 2017). This implies that a competitive leaderboard can work similarly to extrinsic incentives when applied to logistics tasks. Moreover, similar to points and badges, leaderboards can be categorized as goal metrics that provide performance feedback (Zagal et al., 2005). Despite having some adverse effects on motivation, the feedback aspect might explain their usefulness because of its relevance in tracking and enhancing user performance in freight operations and explain the increase in efficiency, as suggested by the feedback intervention theory (Kluger and DeNisi, 1996).

Some of the evaluated outcomes (e.g. fun, attitude, and perceived reality) were only favorable at the operational level, which might be explained by the different characteristics of different decision-making levels. On the one hand, it is complicated to assess whether simulation games at the tactical and strategic levels provide realistic representations due to the long-term consequences of decisions, which are difficult to simulate accurately. On the other hand, attitude change and fun potentially benefit operational tasks most, as some of them are monotonous and repetitive (Tabai et al., 2017). Surprisingly, however, resilience and sustainability were only addressed at the operational level, whereas other behavioral outcomes, like safety, were tackled solely at the strategic level. Overall, the corpus still provided limited evidence on the extent to which gamification improves freight transportation processes and which design choices contribute to favorable outcomes. 
Some limitations include the short-term nature of most studies, the novelty effect, the lack of examination of behavioral outcomes outside game settings and the publication bias limiting the report of adverse effects (Hamari et al., 2014). Therefore, we further propose some recommendations while addressing emerging issues and future research directions.

\section{Gamification in freight transportation}

\subsection{Design recommendations}

Based on the results, we have formulated design recommendations for gamification. Firstly, non-full-fledged gamified approaches are still modestly growing (Koivisto and Hamari, 2019), while full-fledged interventions are predominant in freight transportation. This may be because employing motivational affordances in in-situ practices is more complex than providing a safe environment (i.e. serious and simulation games) to train employees. However, the use of motivational affordances in real settings promotes psychological and behavioral engagement toward repetitive tasks while reducing the costs of creating and maintaining full-fledged games (Chorney, 2012). Thus, our first design recommendation is to consider transportation aspects to be gamified, including users, tasks and contexts. In other words, understanding the nature of the task assists in choosing the most suitable approach: serious and simulation games are an appropriate option for improving learning in an environment that allows employees to simulate and discern the outcomes of actions without risks, while applying motivational affordances to real-world processes is ideal if aiming to improve the efficiency of individual tasks. Still, it is necessary to understand users' psychological needs and how they perceive each task, since affordances can have varying effects depending on the psychological or behavioral outcome (A04).

Given that the development of gamified applications is a recent trend, existing interventions mostly tackle unique challenges, either for specific individuals (e.g. drivers and order pickers) or domains (e.g. energy and space efficiency issues). However, gamification could be wielded as an all-encompassing shared system in an organization, addressing multiple transportation aspects. Some comprehensive interventions began to appear in recent years by teaching an extensive set of skills (A36, A38, A40), creating an awareness of the whole supply chain planning and execution complexity (A06) and promoting the understanding of transportation planning, design and safety (A39). Given their positive outcomes, gamified interventions could be designed to tackle broader challenges of freight transportation by simultaneously targeting different audiences and more complex issues in multiple domains or modalities. This means designers have to consider how transportation processes interact with each other and use suitable motivational affordances to promote further collaboration between users.

Most studies in this review featured achievement affordances, especially undertaking challenges while achieving favorable results in terms of game experience, perceived learning, perceived usefulness, perceived reality, engagement and knowledge. However, other affordances also promote behavioral and psychological benefits, especially considering that users have heterogeneous preferences (A26). While interacting with gamification, users' experiences comprise several aspects, such as their perception of the effectiveness, efficiency, emotional satisfaction and their intention for using the intervention again (Kuniavsky, 2010). Thus, rather than solely aiming for performance goals, designers might also evoke immersive and social aspects by balancing the motivational affordances to create a useful, highly costeffective, pleasant and meaningful experience to direct users toward the desired goals. Also, finding the balance between representation accuracy in simulation games, for instance, and other aspects of the game design that contribute to the overall game experience is an important issue to consider (A01). Furthermore, as simulation games are based on players making in-game decisions that lead to varying outcomes that serve as feedback, the initial step of the simulation game design process should be to identify the most relevant decisions to be implemented (A10). Additionally, to improve future solutions and avoid excessive 
IJPDLM 51,7

702

complexity (which was the major downside of serious and simulation gaming solutions (e.g. A06, A19, A20, A31)), designers should carefully consider the goals of their solutions and the affordances that contribute to achieving these goals. For example, if the goal is shared situational awareness, using multiplayer and cooperation might be a suitable approach, whereas achievement-based affordances should be considered if individual efficiency is the primary goal.

Besides excessive complexity, games mimicking transportation systems should avoid one-sided representations and enhance the holistic understanding of the effects of one's behavior, as transportation systems are complex and their parts do not work in isolation (A02). To include varying perspectives, the design should be conducted or validated by different stakeholders, such as infrastructure managers, carriers and government representatives (A03). Future solutions should also consider the dynamism of transportation systems and enhance the game experience by modifying the simulated environment and scenarios based on player behavior. Tools, such as intelligent algorithms, may aid in this endeavor, potentially leading to increased challenge and keeping the user motivated and engaged (A06).

Additionally, as fluent freight transportation requires collaboration among individuals with differing roles, one of the significant advantages of using physical solutions, such as board games, is that they allow for natural communication, which increases the group experience (A16, A18, A19, A35). However, using such solutions in the freight transportation domain is problematic - even impossible - as it requires users to gather in a single location (A15). Mobile solutions, conversely, allow for location independence but physically isolate the users from one another. To gain the benefits of both approaches, designers should seek solutions that enable fluent interaction among users while being location-independent, so as to allow collaborative learning in dispersed transportation environments.

\subsection{Future directions}

Despite increasing interest over the past decade, the corpus on freight transportation gamification is yet to mature. We identified shortcomings preventing a comprehensive understanding of how freight transportation can benefit from gamification and offer some avenues for further research.

Directing designers by detailing the employed methodology for the gamification implementation and evaluation: The majority of studies provided a brief description of the intervention followed by outcomes. The lack of transparency and detail of the design, implementation and evaluation processes is likely due to most studies' publication venues (i.e. conferences), which often impose page limits due to the thematic emphases. We understand that gamification is a new topic, and researchers are figuring out if it can aid freight transportation. However, the design process should be as rigorous and detailed as the evaluation, since designing requires an understanding of the target audience and the context (Morschheuser et al., 2018). Moreover, the lack of transparency of the evaluation process, mostly detailing how each metric was captured and analyzed, prevents a proper interpretation of the results. Thus, future research should comprehensively report the design and evaluation processes that lead to the achieved benefits. By doing so, studies would provide a more robust understanding of how gamification may assist freight transportation. The description of the gamified intervention and its outcomes would enable comparing the design focuses or possible pitfalls to avoid, according to the desired target audience, tasks, contexts and results.

Exploring the interplay between gamification and data-driven solutions: Given transportation systems have become increasingly intelligent (Siegel et al., 2018), the interplay between gamification and other emerging technologies is a promising trend. 
Advancements in sensor technology and the internet of things enable real-time data collection from the work-floor, allowing monitoring and assisting users in their activities (Guerrero-Ibáñez et al., 2018). However, only one study described a data-driven solution to gamify safe and energy-efficient trucking (A14). Therefore, future research should further design more user-friendly and effective gamification interventions by using the emerging possibilities of intelligent freight transportation. This approach could significantly contribute to the operational functions since it would allow real-time feedback into everyday operations and potentially increase efficiency and well-being in mundane tasks.

Seeking steady evidence of gamification benefits on freight transportation outside gamerelated settings: The current literature mainly investigated gamification psychological effects (e.g. game experience, perceived learning, usefulness and immersion). Behavioral results such as efficiency, safety, resilience and sustainability were less evaluated yet entirely positive. However, the adopted metrics for measuring behavioral outcomes considered only in-game results rather than broader real-world effects, which is likely due to two reasons. Firstly, most of the studies evaluating behavioral outcomes proposed a serious game (A06, A16, A39, A40), so metrics related to knowledge are a reasonable way to assess them. Secondly, operationallevel interventions were the only ones measuring performance inside (A37) and outside the game (A04), showing that short-term results were indeed expected. However, beyond this shortcoming in the operationalization of studies and them being unable to infer about the transfer of gaming and gaming-induced motivations on behavior, we can establish general reasons why gaming or using gamification might not translate into positive changes in action in the "real world." Firstly, novelty is often discussed as a temporal limitation of gamification's effect on behaviors, i.e. the motivational benefits from gamification are short-lived when boredom or perceived staleness of the implementation starts to kick in (Farzan et al., 2008). Secondly, a commonly recognized caveat is the non-congruence of the gamification design and the behaviors and contexts to which it is applied so that motivational affordances are not connected with what gamification aims to promote (Morschheuser et al., 2018). A related problem is that while the gamification would indeed connect with behaviors in the specific context, these behaviors do not always align with the ultimate purpose of gamification. For example, gamification that rewards users for quantitative performance can be detrimental to quality. Thirdly, and relatedly, using gamification may become self-purposeful in itself, and this can lead to a further disconnect with the behaviors being promoted. In this sense, the evidence of gamification's positive effects is limited in the freight transportation domain. Future research should, therefore, employ metrics such as cost-efficiency and compliance, related to real settings, to provide more reliable evidence that gamification improves freight transportation processes.

Pursuing longer-term gamification outcomes in transportation organizations: As previously mentioned, most studies described short-term empirical evaluations, mainly focusing on user perceptions and in-game behaviors. Thus, the literature provides little insight into how gamification interventions can benefit organizations, especially in the long term. More long-term field studies are required to elaborate on how gamification interventions should be implemented and whether continuous usage could lead to individual and organizational transformations. Given that some studies pointed out mixed outcomes such as improving performance while decreasing subjects' motivation (A04), the experimental setting should be rethought. Short-term evaluations and laboratory experiments are unlikely to extensively uncover such adverse effects. Therefore, understanding the whole variety of effects that gamification can have on individuals and group dynamics provides another rationale for long-term field studies in freight transportation organizations.

Investigating how gamification can advance social and environmental aspects of freight transportation: The evaluated in-game metrics were solely related to economic factors 
IJPDLM

51,7

704 (e.g. profit, operational costs). Moreover, outcomes related to sustainability were examined exclusively on the operational level, and safety on the strategic level. Therefore, the corpus provides little insight on how to enhance these issues through gamification holistically. However, considering that social and environmental aspects are some of the grand challenges of transportation systems (Kaewunruen et al., 2016), we recognize that gamification could improve them similarly to the economic aspects. While none of the studies covered environmental issues, only one of them (A30) presented a shared-economy proposal, in which haulage companies could make offers to transport the customers' commodities. Although social and environmental aspects often go hand in hand with economic aspects (García-Arca et al., 2014), sometimes, improving cost-efficiency can juxtapose with safety. Setting strict productivity goals may lead to a considerable strain on employees, increasing accident rates (Useche et al., 2018). Thus, there are plenty of opportunities for future works to explore gamification benefits concerning social (e.g. social media, shared economy), environmental and safety aspects.

Addressing long-term system resilience: Outcomes related to resilience were only examined on the operational level by implementing serious and simulation games tackling disruption handling in port operations (A16) and information exchange during transport disruptions (A18). However, globalization and the increasing interconnectedness of supply chains has made them vulnerable to global-scale disruptive events, such as pandemics, which requires novel solutions to address resilience on a large scale (Ivanov and Dolgui, 2020). Therefore, future gamification research should not just address this crucial issue on the level of day-today transportation operations, but seek to implement gameful solutions that tackle resilience on tactical and strategic levels through transportation system infrastructure, design and policy.

\section{Limitations}

Several mitigation actions were taken to suppress the limitations of this review. For instance, we refined the search by testing several synonyms and broader terms of each keyword to ensure proper string construction (Ampatzoglou et al., 2019). Two evaluators screened all of the studies returned from the search to avoid selection bias, culminating in an almost perfect agreement. These evaluators also discussed and agreed upon each marginal case. After screening, we ensured the excellence of the studies to avoid quality bias. We also prevented data extraction and researcher bias by employing a classification scheme and cross-checking all of the included studies. Regarding repeatability, this systematic review developed a protocol (detailed in Section 3) and documented all parts of the process. However, limitations are present in the study, including the lack of a snowballing process to identify missing studies and publication bias (considering that only one search engine was employed), and some selection criteria might, therefore, have excluded relevant studies (due to language or access, for instance).

\section{Conclusions}

This systematic literature review has described the status quo of gamification in freight transportation while proposing design guidelines and research agenda. The extant corpus proposed several gamification interventions aiming to improve aspects of freight transportation. Studies mainly focused on road and water modes, without considering intermodality, and aimed to enhance operational-level tasks such as truck driving and managing disruptions at maritime ports (RQ1). Most studies reproduced real environments through simulation games, employing achievement (e.g. challenges, points), immersion (e.g. role-playing) and social (e.g. cooperation) affordances (RQ2). Overall, behavioral 
(e.g. knowledge and performance) and psychological (e.g. perceived learning and usefulness, fun and engagement) outcomes were positive and measured through quantitative and qualitative methods (RQ3). Mixed but mostly positive outcomes also appeared in terms of game experience, perceived reality, motivation, satisfaction and attitude. Whereas simulation games contributed to better outcomes in freight transportation by teaching decision making on all levels, serious games focused on efficiency at operational and strategic levels by allowing users to learn about complex transportation concepts and resource allocation strategies through fictional, simplified representations. Moreover, gamified interventions focused on the operational level and contributed to adopting novel systems by creating useful and engaging interfaces while improving learning and tackling monotonous tasks to enhance staff motivation (RQ4).

We suggest future developments to understand the complexity of the tasks, to propose suitable gamification interventions, target different audiences and balance motivational affordances. Future research should also provide further details about design methodology and use data-driven approaches while searching for longer-term outcomes, especially those related to social and environmental aspects, outside game settings.

\section{References}

Ames, C. and Archer, J. (1988), "Achievement goals in the classroom: students' learning strategies and motivation processes”, Journal of Educational Psychology, Vol. 80 No. 3, pp. 260-267.

Ampatzoglou, A., Bibi, S., Avgeriou, P., Verbeek, M. and Chatzigeorgiou, A. (2019), "Identifying, categorizing and mitigating threats to validity in software engineering secondary studies", Information and Software Technology, Vol. 106, pp. 201-230.

Bandura, A. (1986), Social Foundations of Thought and Action: A Social Cognitive Theory, PrenticeHall, Englewood Cliffs.

Baptista, G. and Oliveira, T. (2019), "Gamification and serious games: a literature meta-analysis and integrative model", Computers in Human Behavior, Vol. 92, pp. 306-315.

Boy, G. (2013), "Orchestrating situation awareness and authority in complex socio-technical systems", Complex Systems Design and Management, Springer, Berlin, Heidelberg.

CASP (2017), Critical Appraisal Skills Programme (CASP) Systematic Review Checklist, available at: https://casp-uk.net/casp-tools-checklists/.

Chorney, A.I. (2012), "Taking the game out of gamification”, Dalhousie Journal of Interdisciplinary Management, Vol. 8, pp. 1-14.

Creswell, J.W. (2014), A Concise Introduction to Mixed Methods Research, SAGE Publications, Thousand Oaks.

Csikszentmihalyi, M. (1993), The Evolving Self: A Psychology for the Third Millennium, HarperCollins Publishers, New York.

Deterding, S., Dixon, D., Khaled, R. and Nacke, L. (2011), "From game design elements to gamefulness: defining 'gamification", Proceedings of the 15th International Academic MindTrek Conference on Envisioning Future Media Environments - MindTrek, Vol. 11, p. 9.

Ellington, H., Addinall, E., Percival, F. and Page, K. (1981), Games and Simulations in Science Education, Nichols Pub, New York.

European Union (2019), EU Transport in Figures: Statistical Pocketbook 2019, Publications Office of the European Union, Luxembourg.

Evangelista, P., Santoro, L. and Thomas, A. (2018), "Environmental sustainability in third-party logistics service providers: a systematic literature review from 2000-2016”, Sustainability, Vol. 10 No. 5, p. 1627.
Gamification in freight transportation 
IJPDLM

51,7

706

Fagnant, D.J. and Kockelman, K. (2015), "Preparing a nation for autonomous vehicles: opportunities, barriers and policy recommendations", Transportation Research Part A: Policy and Practice, Vol. 77, pp. 167-181.

Farzan, R., DiMicco, J.M., Millen, D.R., Dugan, C., Geyer, W. and Brownholtz, E.A. (2008), "Results from deploying a participation incentive mechanism within the enterprise", Proceedings of CHI, 2008, pp. 563-572.

García-Arca, J., Carlos Prado-Prado, J. and Trinidad Gonzalez-Portela Garrido, A. (2014), "Packaging logistics: promoting sustainable efficiency in supply chains", International Journal of Physical Distribution and Logistics Management, Vol. 44 No. 4, pp. 325-346.

Ghiani, G., Laporte, G. and Musmanno, R. (2013), Introduction to Logistics Systems Management, 2nd ed., John Wiley and Sons, Chichester.

Gligor, D.M. and Holcomb, M.C. (2012), "Understanding the role of logistics capabilities in achieving supply chain agility: a systematic literature review", Supply Chain Management: An International Journal, Vol. 17 No. 4, pp. 438-453.

Guerrero-Ibáñez, J., Zeadally, S. and Contreras-Castillo, J. (2018), "Sensor technologies for intelligent transportation systems", Sensors, Vol. 18 No. 4, p. 1212.

Hamari, J. (2019), "Gamification”, The Blackwell Encyclopedia of Sociology, John Wiley and Sons, pp. 1-3.

Hamari, J., Koivisto, J. and Sarsa, H. (2014), "Does gamification work? - A literature review of empirical studies on gamification”, 47th Hawaii International Conference on System Sciences, pp. 3025-3034.

Hamari, J., Shernoff, D.J., Rowe, E., Coller, B., Asbell-Clarke, J. and Edwards, T. (2016), “Challenging games help students learn: an empirical study on engagement, flow and immersion in gamebased learning", Computers in Human Behavior, Vol. 54, pp. 170-179.

Hazen, B.T. and Byrd, T.A. (2012), "Toward creating competitive advantage with logistics information technology”, International Journal of Physical Distribution and Logistics Management, Vol. 42 No. 1, pp. 8-35.

Hesse, M. (2016), The City as a Terminal: The Urban Context of Logistics and Freight Transport, Routledge, New York.

Huotari, K. and Hamari, J. (2017), "A definition for gamification: anchoring gamification in the service marketing literature”, Electronic Markets, Vol. 27 No. 1, pp. 21-31.

Ivanov, D. and Dolgui, A. (2020), "Viability of intertwined supply networks: extending the supply chain resilience angles towards survivability. A position paper motivated by COVID-19 outbreak”, International Journal of Production Research, Vol. 58 No. 10, pp. 2904-2915.

Kaewunruen, S., Sussman, J.M. and Matsumoto, A. (2016), "Grand challenges in transportation and transit systems", Frontiers in Built Environment, Vol. 2 No. 4, pp. 1-5.

Kluger, A.N. and DeNisi, A. (1996), "The effects of feedback interventions on performance: a historical review, a meta-analysis, and a preliminary feedback intervention theory", Psychological Bulletin, Vol. 119 No. 2, pp. 254-284.

Koivisto, J. and Hamari, J. (2019), "The rise of motivational information systems: a review of gamification research", International Journal of Information Management, Vol. 45, pp. 191-210.

Kuniavsky, M. (2010), Smart Things: Ubiquitous Computing User Experience Design, Morgan Kaufmann, Burlington, CA.

Landis, J.R. and Koch, G.G. (1977), "The measurement of observer agreement for categorical data", Biometrics, Vol. 33 No. 1, p. 159.

Lethbridge, T.C., Sim, S.E. and Singer, J. (2005), "Studying software engineers: data collection techniques for software field studies", Empirical Software Engineering, Vol. 10 No. 3, pp. 311-341.

Liu, H. (2003), Pipeline Engineering, CRC Press, Boca Raton. 
Locke, E.A. and Latham, G.P. (1990), A Theory of Goal Setting and Task Performance, Prentice-Hall, Englewood Cliffs.

Loeb, P.D. and Clarke, W.A. (2007), "The determinants of truck accidents", Transportation Research Part E: Logistics and Transportation Review, Vol. 43 No. 4, pp. 442-452.

Mekler, E.D., Brühlmann, F., Tuch, A.N. and Opwis, K. (2017), "Towards understanding the effects of individual gamification elements on intrinsic motivation and performance", Computers in Human Behavior, Vol. 71, pp. 525-534.

Michael, D. and Chen, S. (2006), Serious Games: Games that Educate, Train, and Inform, Thomson Course Technology, Boston.

Morschheuser, B., Hassan, L., Werder, K. and Hamari, J. (2018), "How to design gamification? A method for engineering gamified software", Information and Software Technology, Vol. 95, pp. 219-237.

Paré, G., Trudel, M.C., Jaana, M. and Kitsiou, S. (2015), "Synthesizing information systems knowledge: a typology of literature reviews", Information and Management, Vol. 52 No. 2, pp. 183-199.

Pei-Ju, W., Mu-Chen, C. and Tsau, C.K. (2017), "The data-driven analytics for investigating cargo loss in logistics systems", International Journal of Physical Distribution and Logistics Management, Vol. 47 No. 1, pp. 68-83.

Petersen, K., Vakkalanka, S. and Kuzniarz, L. (2015), "Guidelines for conducting systematic mapping studies in software engineering: an update", Information and Software Technology, Vol. 64, pp. 1-18.

Rushton, A. (2017), The Handbook of Logistics and Distribution Management: Understanding the Supply Chain, 6th revised ed., Kogan Page, London.

Ryan, R.M., Rigby, C.S. and Przybylski, A. (2006), "The motivational pull of video games: a selfdetermination theory approach", Motivation and Emotion, Vol. 30 No. 4, pp. 347-363.

Schlesselman, J.J. (1982), Case-control Studies: Design, Conduct, Analysis, Oxford University Press, New York, Vol. 2.

Seijts, G.H., Latham, G.P., Tasa, K. and Latham, B.W. (2004), "Goal setting and goal orientation: an integration of two different yet related literatures", Academy of Management Journal, Vol. 47 No. 2, pp. 227-239.

Seuring, S. and Gold, S. (2012), "Conducting content-analysis based literature reviews in supply chain management”, Supply Chain Management, Vol. 17 No. 5, pp. 544-555.

Shang, K.C. and Tseng, W.J. (2010), "A risk analysis of stevedoring operations in seaport container terminals", Journal of Marine Science and Technology, Vol. 18 No. 2, pp. 201-210.

Siegel, J.E., Erb, D.C. and Sarma, S.E. (2018), "A survey of the connected vehicle landscapearchitectures, enabling technologies, applications, and development areas", IEEE Transactions on Intelligent Transportation Systems, Vol. 19 No. 8, pp. 2391-2406.

Sivilevičius, H. (2011), "Modelling the interaction of transport system elements", Transport, Vol. 26 No. 1, pp. 20-34.

Stock, J.R. and Lambert, D.M. (2001), Strategic Logistics Management, 4th ed., McGraw-Hill/Irwin, New York.

Tabai, B.H., Bagheri, M., Sadeghi-Firoozabadi, V. and Shahidi, V. (2017), "The relationship between train drivers' attention and accident involvement”, 2017 4th International Conference on Transportation Information and Safety (ICTIS), pp. 1034-1039.

Takemura, K. (2014), Behavioral Decision Theory. Psychological and Mathematical Descriptions of Human Choice Behavior, Springer Japan, Tokyo.

Useche, S.A., Gómez, V., Cendales, B. and Alonso, F. (2018), "Working conditions, job strain, and traffic safety among three groups of public transport drivers", Safety and Health at Work, Vol. 9 No. 4, pp. 454-461.

Gamification in freight transportation 
IJPDLM 51,7

Verbraeck, A., Kurapati, S. and Lukosch, H. (2016), "Serious games for improving situational awareness in container terminals", Logistics and Supply Chain Innovation, Springer International Publishing, pp. 413-431.

Wanick, V. and Bui, H. (2019), "Gamification in Management: a systematic review and research directions", International Journal of Serious Games, Vol. 6 No. 2, pp. 57-74.

Warmelink, H., Koivisto, J., Mayer, I., Vesa, M. and Hamari, J. (2020), "Gamification of production and logistics operations: status quo and future directions", Journal of Business Research, Vol. 106, pp. 331-340.

Webster, J. and Watson, R.T. (2002), "Analyzing the past to prepare for the future: writing a literature review”, MIS Quarterly, pp. 13-23.

Yee, N. (2006), "Motivations for play in online games", Cyber Psychology and Behavior, Vol. 9 No. 6, pp. $772-775$.

Zagal, J.P., Mateas, M., Fernández-Vara, C., Hochhalter, B. and Lichti, N. (2005), "Towards an ontological language for game analysis", Proceedings of DiGRA 2005 Conference: Changing Views - Worlds in Play, p. 13.

Zeng, A.Z. and Rossetti, C. (2003), "Developing a framework for evaluating the logistics costs in global sourcing processes: an implementation and insights", International Journal of Physical Distribution and Logistics Management, Vol. 33 No. 9, pp. 785-803.

\section{Appendix}

A01. Anand, N., Meijer, D., van Duin, J.H.R., Tavasszy, L. and Meijer, S. (2016), "Validation of an agent based model using a participatory simulation gaming approach: the case of city logistics", Transportation Research Part C: Emerging Technologies, Vol. 71, pp. 489-499.

A02. Battini, D., Faccio, M., Persona, A. and Sgarbossa, F. (2009), "Logistic GameTM: learning by doing and knowledge-sharing”, Production Planning and Control, Vol. 20 No. 8, pp. 724-736.

A03. Bekebrede, G., Lo, J. and Lukosch, H. (2015), "Understanding complex systems through mental models and shared experiences: a case study", Simulation and Gaming, Vol. 46 No. 5, pp. 536-562.

A04. Bräuer, P. and Mazarakis, A. (2019), "Badges or a leaderboard? How to gamify an augmented reality warehouse setting", CEUR Workshop Proceedings, Vol. 2359, pp. 229-240.

A05. de Leao, A.G. (2016), "Transportation services game: a practical tool to teach outsourcing concepts on logistics", Games and Learning Alliance, Springer International Publishing, pp. 368-374.

A06. de Souza, R., William, L., Timperio, G. and Abdul Rahim, Z.B. (2018), "Simulation model and simulation-based serious gaming in humanitarian logistics", 2018 Winter Simulation Conference (WSC), pp. 57-67.

A07. Duin, H., Gorldt, C., Thoben, K.D. and Pawar, K. (2017), "Learning in ports with serious gaming", 2017 International Conference on Engineering, Technology and Innovation (ICE/ITMC), pp. 431-438.

A08. Freese, M. and Drees, S. (2016), "D-CITE - a serious game to analyze complex decision-making in air traffic management", Games and Learning Alliance, Springer International Publishing, pp. 23-31.

A09. Freese, M., Kurapati, S., Lukosch, H.K., Groen, D., Kortmann, R. and Verbraeck, A. (2018), "Addressing challenges of planning in multimodal transportation Nodes with simulation games", Intersections in Simulation and Gaming, Springer International Publishing, pp. 254-275.

A10. Fumarola, M., van Staalduinen, J.-P. and Verbraeck, A. (2012), "A ten-step design method for simulation games in logistics management", Journal of Computing and Information Science in Engineering, Vol. 12 No. 1, 011006. 
A11. Gentry, J.W., Jackson, G.C. and Morgan, F.W. (1988), "PROLOG: a business logistics simulation game", Journal of Marketing Education, Vol. 10 No. 3, pp. 74-83.

A12. Haidon, C., Ecrepont, A., Girard, B. and Menelas, B.-A.J. (2017), "A driving simulator designed for the Care of trucker suffering from post-traumatic stress disorder", Serious Games and Edutainment Applications, Springer International Publishing, pp. 411-431.

A13. Hupont, I., Gracia, J., Sanagustin, L. and Gracia, M.A. (2015), "How do new visual immersive systems influence gaming QoE? A use case of serious gaming with Oculus Rift", 2015 Seventh International Workshop on Quality of Multimedia Experience (QoMEX), pp. 1-6.

A14. Klemke, R., Kravcik, M. and Bohuschke, F. (2014), "Energy-efficient and safe driving using a situationaware gamification approach in logistics", Games and Learning Alliance, Springer International Publishing, pp. 3-15.

A15. Klemke, R., Kurapati, S., Lukosch, H. and Specht, M. (2015a), "Lessons learned from creating a mobile version of an educational board game to increase situational awareness", Design for Teaching and Learning in a Networked World, pp. 183-196.

A16. Klemke, R., Kurapati, S., Lukosch, H. and Specht, M. (2015b), "Transferring an educational board game to a multi-user mobile learning game to increase shared situational awareness", Learning and Collaboration Technologies, Springer International Publishing, pp. 583-594.

A17. Kola, D., Giannikas, V. and McFarlane, D. (2012), "Travel behaviour applied in freight transportation using intelligent products", CCCA12, pp. 1-6.

A18. Kourounioti, I., Kurapati, S., Lukosch, H., Tavasszy, L. and Verbraeck, A. (2018), "Simulation games to study transportation issues and solutions: studies on synchromodality", Transportation Research Record: Journal of the Transportation Research Board, Vol. 2672 No. 44 , pp. $72-81$.

A19. Kurapati, S., Lukosch, H., Verbraeck, A. and Brazier, F.M.T. (2015), "Improving resilience in intermodal transport operations in seaports: a gaming approach", EURO Journal on Decision Processes, Vol. 3 Nos 3-4, pp. 375-396.

A20. Kurapati, S., Kourounioti, I., Lukosch, H., Tavaszzy, L., Verbraeck, A., van Veen, L. and van Nuland, B. (2017), "Exploring challenges and solutions for container transportation using rail: a modelling and simulation gaming study", 2017 5th IEEE International Conference on Models and Technologies for Intelligent Transportation Systems (MT-ITS), pp. 158-163.

A21. Kurapati, S., Freese, M., Kourounioti, I., Lukosch, H., Bekebrede, G., Smit, T., van Meijeren, J., van Nuland, B. and van Veen, L. (2018), "Attitude measurement with board games in transportation Nodes", Simulation Gaming. Applications for Sustainable Cities and Smart Infrastructures, Springer International Publishing, pp. 148-157.

A22. Kurapati, S., Kourounioti, I., Lukosch, H., Tavasszy, L. and Verbraeck, A. (2018), "Fostering sustainable transportation operations through corridor management: a simulation gaming approach", Sustainability, Vol. 10 No. 2, p. 455.

A23. Liu, C.-L. (2017), "Using a video game to teach supply chain and logistics management", Interactive Learning Environments, Vol. 25 No. 8, pp. 1009-1024.

A24. Lukosch, H. and Comes, T. (2019), "Gaming as a research method in humanitarian logistics", Journal of Humanitarian Logistics and Supply Chain Management, Vol. 9 No. 3, pp. 352-370.

A25. Lukosch, H., Kurapati, S., Groen, D. and Verbraeck, A. (2016), "Microgames for situated learning: a case study in interdependent planning", Simulation and Gaming, Vol. 47 No. 3, pp. 346-367.

A26. Marcucci, E., Gatta, V. and Le Pira, M. (2018), "Gamification design to foster stakeholder engagement and behavior change: an application to urban freight transport", Transportation Research Part A: Policy and Practice, Vol. 118, pp. 119-132.

A27. Meesters, K., Olthof, L. and Van de Walle, B. (2014), "Disaster in my Backyard: a serious game to improve community disaster resilience", Proceedings of the European Conference on Gamesbased Learning, pp. 714-722.
Gamification in freight transportation 
IJPDLM 51,7

\section{0}

A28. Menelas, B.-A.J., Haidon, C., Ecrepont, A. and Girard, B. (2018), "Use of virtual reality technologies as an action-cue exposure Therapy for truck drivers suffering from post-traumatic stress disorder", Entertainment Computing, Vol. 24, pp. 1-9.

A29. Olexová, C. and Gajdoš, J. (2016), "Logistics simulation game proposal - a tool for employees' induction", Quality Innovation Prosperity, Vol. 20 No. 2, p. 53.

A30. Pacheco, F., Furtado, F. and Filho, E. (2018), "Stepbox: a proposal of share economy transport service", 2018 13th Iberian Conference on Information Systems and Technologies (CISTI), pp. 1-6.

A31. Pudło, P. and Gavurová, B. (2013), "Experimental teaching methods in higher educationpractical application”, International Multidisciplinary Scientific GeoConference Surveying Geology and Mining Ecology Management, SGEM, Vol. 2, pp. 423-428.

A32. Putz, L.M., Schmidt-Kraepelin, M., Treiblmaier, H. and Sunyaev, A. (2018), "The influence of gamified workshops on students' knowledge retention", CEUR Workshop Proceedings, CEURWS, pp. 40-47.

A33. Putz, L.M., Hofbauer, F. and Mates, M. (2019), "A vignette study among order pickers about the acceptance of gamification”, CEUR Workshop Proceedings, CEUR-WS, pp. 154-166.

A34. Remi-Omosowon, A., Cant, R. and Langensiepen, C. (2016), "Applying gamification Principles to a container loading system in a warehouse environment", 2016 UKSim-AMSS 18th International Conference on Computer Modelling and Simulation (UKSim), pp. 79-84.

A35. Spil, T.A.M., Versluijs, W. and Vliegen, I. (2019), "Care 4 supply”, 2019 IEEE 7th International Conference on Serious Games and Applications for Health (SeGAH), pp. 1-8.

A36. Titton, L.A. (2014), "Parameterised business simulation game development for education in supply chain management and logistics", Frontiers in Gaming Simulation, Springer International Publishing, pp. 230-236.

A37. Wang, Q. and Abbas, M. (2017), “Game suite for transportation education”, ASEE Annual Conference and Exposition, Conference Proceedings, 2017-June.

A38. Wang, Q. and Abbas, M. (2018), "Designing web-games for transportation engineering education", Computer Applications in Engineering Education, Vol. 26 No. 5, pp. 1699-1710.

A39. Wang, F., Wang, Y. and Hu, X. (2017), "Gamification teaching reform for higher vocational education in China: a case study on layout and management of distribution center", International Journal of Emerging Technologies in Learning, Vol. 12 No. 9, pp. 130-144.

A40. Winkelhaus, S. and Grosse, E.H. (2020), "Logistics 4.0: a systematic review towards a new logistics system", International Journal of Production Research, Vol. 58 No. 1, pp. 18-43.

\section{Corresponding author}

Ana Carolina Tomé Klock can be contacted at: ana.tomeklock@tuni.fi

For instructions on how to order reprints of this article, please visit our website:

www.emeraldgrouppublishing.com/licensing/reprints.htm

Or contact us for further details: permissions@emeraldinsight.com 